\title{
Building life cycle applied to refurbishment of a traditional building from Oporto, Portugal
}

\author{
Fernanda Rodrigues ${ }^{\mathrm{a}}$, Raquel Matos ${ }^{\mathrm{a}}$, Ana Alves ${ }^{\mathrm{c}}$, Paulo Ribeirinho ${ }^{\mathrm{a}}$, Hugo Rodrigues ${ }^{\mathrm{b}, *}$ \\ ${ }^{\text {a }}$ RISCO, University of Aveiro, Aveiro, Portugal \\ ${ }^{\mathrm{b}}$ RISCO, Polytecnic Institut of Leiria, Leiria, Portugal \\ ${ }^{c}$ University of Aveiro, Aveiro, Portugal
}

\section{A R T I C L E I N F O}

\section{Keywords:}

Service life

Life cycle costs

Planning

BIM

\begin{abstract}
A B S T R A C T
Buildings management along with its life cycle is currently an issue that requires a great optimisation considering the high cost associated with the buildings use and due to the operation and maintenance costs. The number of existing buildings needing refurbishment actions justify the need of an intervention model that optimise its service life after the refurbishment process. So, a refurbishment, maintenance and costs planning should be established and guided by value for money principles. The aim of this paper is to analyse the application of Buildings Life Cycle Management (BLCM) to a case study under a refurbishment process, to study the specific solutions and to assess the correspondent service life using the factor method according the ISO 15686 family. With this study, was possible to assess solutions and refurbishment conditions in terms of durability, when compared between the different proposals. In order to improve the case study Building Life Cycle maintenance, in addition, was applied Building Information Modelling (BIM), as BLCM is connected with BIM in order to highlight the importance of their inter-relationship. This study concludes about the most advantageous type of maintenance, how BIM can contributes to BLCM and how can improve maintenance plans.

Thus, this study contributes to highlight the importance of preventive maintenance, to promote its implementation and consequently, to use maintenance plans reducing life cycle cost and increasing materials service life.
\end{abstract}

\section{Introduction}

The knowledge to model, analyse, design, maintain, monitor, manage, predict and optimise the life-cycle performance of structures and infrastructures under uncertainty is continually growing. However, the infrastructure or the structure is no longer within desired levels of performance and safety, decisions regarding its systems should be supported by an integrated reliability-based life-cycle multi-objective optimisation framework by considering, among other factors, the likelihood of successful performance and the total expected cost accrued over the entire life cycle [21].

The main objectives of this paper are to analyse the Building life cycle performance assessment, maintenance, monitoring, management and optimisation of construction systems under uncertainty, and its challenges for a specific building, and then connect Building Life Cycle Management (BLCM) and Building Information Modelling (BIM) and highlight the importance of BIM in BLCM.

This study is organised as follow. Firstly, it reviews the related research about Building Life Cycle Management (BLCM), Life Cycle Cost (LCC), Life Cycle Assessment (LCA), Building Information Modelling (BIM), as they are key concepts used in this study. Based on above, it presents the methodology applied, the study about LCC done and depicts the BIM model developed aiming building life cycle maintenance. Finally, the study ends with conclusions.

\section{Building Life Cycle Management}

Building Life Cycle Management (BLCM methodology is constituted by planning, design construction, operation and maintain phases of the building during its life cycle. BLCM covers whole processes of construction, using the digital way to create, manage and share the asset Information and based on the integrated virtual building information model and collaboration, is seek to design-construction-management process integration [29]. Building life cycle management is a holistic business concept developed to manage a building and its lifecycle including materials, construction process, quality of workmanship,

\footnotetext{
* Corresponding author.

E-mail addresses: mfrodrigues@ua.pt (F. Rodrigues),rvpm@ua.pt (R. Matos), anadalves@ua.pt (A. Alves), RibeirinhoSoares@ua.pt (P. Ribeirinho), hugo.f.rodrigues@ipleiria.pt (H. Rodrigues).
} 
analysis of results, test specifications, environmental component information, quality standards, engineering requirements, changing orders, manufacturing procedures, component suppliers, etc. Saaksvuori, Immonem [30]. To implement the life cycle management, it is very important to know how to create and manage the data and the information correctly [29]. Building life cycle management capabilities include workflow, program management and speed up management operations and it is a collaborative backbone allowing people throughout extended enterprises to work together associated later with Life Cycle Assessment and with Life Cycle Cost [31].

Building life cycle management makes possible to control the whole lifespan of a building and the information connected with it. Efficient building life cycle management enables the owners to compare different solutions, to find the better one and this means that is cheaper and less harmful to all over the life cycle [30]. Therefore, an initial higher investment in quality materials can have a more favourable return over the useful life of the asset, since the overall durability of building depends on the durability of the individual components and materials [27].

Considering that every Building is unique, the need for maintenance, repair and asset renewals varies depending on many factors, including: the quality of construction, design details, exposure conditions and the standard of care given by the owner and their property management team. Notwithstanding the differences between individual buildings, it has been determined that many of them follow a similar pattern as they pass through different stages in their respective lifecycles [7].

\subsection{Life cycle stages}

Life cycle begin with material manufacturing that includes removal of raw material from earth, transportation to the manufacturing location, manufacture of finished intermediate materials, building product fabrication, packaging and distribution of building products [2].

Building construction sector includes activities relating to construction of new buildings or refurbishment of existent ones, typically including: transportation of materials and products to the construction site, use of power tools and equipment during building construction, on-site fabrication, and energy use for site works. Impacts evaluation of construction fall into this stage in current LCA - Life Cycle Assessment methods [2]. Nevertheless, there are the use and maintenance stage, the longer one, that refers to building operation phase, which includes all activities related to building's use throughout its life cycle. These activities contain maintenance of comfort conditions inside the building, energy consumption, water use, and environmental waste generation. It also takes into account the repair and replacement of building assemblies and systems. Transport and equipment used for repair and replacement in this phase also are considered ([2] and [3]). Finally, there is the end of life, that includes the energy consumed and the environmental waste produced due to building demolition and disposal of materials to landfills sites, including the transport of dismantled building materials, recycling and reuse activities related to demolition waste, depending on the availability of data [3].

Note that reviews of previous LCA studies based the description of building life cycle stages described above. Each life cycle stage may or may not include all the activities described, depending on the scope and details of each project [2].

\subsection{Life Cycle Assessment (LCA) and Life Cycle Cost (LCC)}

Life Cycle Assessment comprise the assessment of the environmental impact of a product or service throughout its life cycle [6]. The LCA presents 3 variants, depending on the phases of the life cycle that are being studied: Cradle-to-Grave, Cradle-to-Gate and Cradle-to-Cradle [25],

According to ISO [17] and Dixon [6], Life Cycle Cost is the cost of an asset or its part throughout its life cycle, while fulfilling the performance requirements. These costs calculated by expression (1) [35].

$L C C=C+P V_{\text {Recurring }}-P V_{\text {Residual }- \text { value }}$

Where:

LCC is the life cycle cost, $\mathrm{C}$ is the Year 0 of construction costs (hard and soft costs - hard costs refer to labour costs, material and equipment's costs. Soft costs to construction site cost, architectural and engineering fees, pre and post-construction expenses, like movable furniture and equipment). $P V_{\text {Recurring }}$ is the present value of all recurring costs (utilities, maintenance, replacements, service, and others.). $P V_{\text {Residual-value }}$ is the present value of the residual value at the end of the life study (that it is recommended to be 0 ).

This work will focus on the cost, but is important to recognise that the choice of materials/products for each project has direct and indirect impacts on the environment, as well as in the capital and operational costs. Carrying out LCC and LCA exercise enables project teams to demonstrate that they have considered the environmental and economic impacts of their decisions process and chosen the most appropriate materials/products for its job or task [6]. On building life cycle, the goal for minimizing the building costs and its environmental impacts, either in construction and maintenance stage or end of life is crucial. If it is possible to forecast the budget and maintenance activities in the building design phase, it is also possible to decrease costs over the building service life.

Considering life cycle analysis is appropriate for comparing design alternatives or operations schemes for managers and owners decisionmaking support [23]. So, to develop this study, the understanding of the conceptual methodology behind this process is necessary, and is described in the next section.

\subsubsection{Conceptual methodology}

In this work, a case study was used, in which, the characterization of a building under refurbishment is made followed by the determination of materials' service life applying the factorial method. This method is a deterministic approach, according to ISO [16], that identifies the influence factors of components' service life, based on the multiplication of these factors by the components' reference service life (RSLC). According to ISO [16], reference service life is a service life known through a particular set of in-use conditions. However, project-specific in-use conditions are usually different from reference in-use conditions, so it is necessary to apply the Factorial Method, multiplying the RSLC by a number of factors, each one reflecting the difference between the reference conditions and in-use conditions [18].

The advantage of Factorial Method is that allows considering the factors that are likely to contribute to variations in service life, therefore applied in this case study. To use this method, is possible to bring together the experience of designers, observations, intentions of managers, and manufacturers. Therefore, this method does not provide an assurance of a service life, but gives an empirical estimation based on the available information [16]. However, this method has disadvantages too: assumes a constant materials degradation rate, which is not real, and the assignment of the same weight to different modifying factors that may have different influence on the durability of a product [24]. Several authors have used this method and modifying factors to estimate the service life of building elements [32]. Lopes [24] applied the factorial method to calculate the service life prediction of facades claddings, Souza [34] to evaluate the life cycle of wooden and concrete poles.

According to ISO [16] expression (2) estimates service life, and the meaning and applicability of the factors are in Table 1.

$E S L C=R S L C \times$ factor $A \times$ factor $B \times$ factor $C \times$ factor $D \times$ factor $E$ $\times$ factor $F$

Were: 
Table 1

Factors for degradation of materials and components (ISO 15686-1: 2008).

\begin{tabular}{|c|c|c|c|c|}
\hline Agents & Factor & & Value & actors \\
\hline \multirow{3}{*}{$\begin{array}{l}\text { Agent related to the } \\
\text { inherent quality } \\
\text { characteristics }\end{array}$} & Factor A & $\begin{array}{l}\text { Quality of } \\
\text { components }\end{array}$ & & \\
\hline & Factor B & Design level & & \\
\hline & Factor C & $\begin{array}{l}\text { Work execution } \\
\text { level }\end{array}$ & Value & $\begin{array}{l}\text { Deviation } \\
\text { from VUR }\end{array}$ \\
\hline \multirow[t]{3}{*}{ Environment } & Factor D & $\begin{array}{l}\text { Indoor } \\
\text { environmental }\end{array}$ & 0.8 & $\begin{array}{l}\text { Negative } \\
\text { influence }\end{array}$ \\
\hline & & & 1.0 & $\begin{array}{l}\text { Without } \\
\text { deviation }\end{array}$ \\
\hline & Factor E & $\begin{array}{l}\text { Outdoor } \\
\text { environmental }\end{array}$ & 1.2 & $\begin{array}{l}\text { Positive } \\
\text { influence }\end{array}$ \\
\hline \multirow[t]{2}{*}{ Operation conditions } & Factor F & In-use conditions & & \\
\hline & Factor G & Maintenance level & & \\
\hline
\end{tabular}

Life cycle performance of construction defined in [18].

ESLC: is the estimated service life of a component (or assembly)

RSLC: is the reference service life of a component (or assembly) [16]

During the application of this method, due to the lack of factor databases and knowledge how to define and represent the behaviour of performance levels over building life cycle, were faced some difficulties.

According with the building life cycle performance curve defined by [18], buildings' and its components performance levels change influencing the service life. Over the life cycle, the building performance level is going to decrease but with each maintenance action, it is possible to return to the initial level or increase it and consequently increase the service life of components. Since, during this study, it was not possible to obtain this curve, for the case study, to simulates this behaviour, the service life was increased by a rate of $5 \%$ (a value considered a reasonable value taking into account the existent materials to replace, when the building component is subject to preventive maintenance action).

To define an accurate performance-degradation curve a data record is necessary, based on empirical knowledge, considering the performance improvement introduced at each maintenance action and the historical of the degradation over the years.

After the evaluation of the service life of elements, considering different alternatives for each one, through their initial maintenance and replacement costs, taking into account the frequency of interventions according with the maintenance plan, it is possible to calculate the LCC by expression (1). The maintenance plan should contain all the information to prevent and monitor the performance of elements, systematize a set of inspection, cleaning, repair and replacement operations, and it should include the respective periodicities [12].

After obtaining the LCC the future value of money can be estimated by the Net Present Value (NPV). The time value of money depends on inflation and opportunity costs [35]. This means that it is necessary to provide maintenance costs in the future. To forecast future costs, the Net Present Value (NPV) consider a discount rate, which reflect the interest rate used for discounting reflecting an investor's opportunity cost of money over time [14]. The expression (3) translate the NPV [35].

$N P V=\sum_{t=0}^{n} \frac{C F_{t}}{(1+k)^{t}}$

Where $C F_{t}$ is the value of cash flow (positive or negative) generated by the project in the $t$ period, $k$ is the discount rate, $t$ is a period in years and $n$ is the number of years of the project service life. Discount rate is usually used in cases where economic viability of investment and enterprises is being evaluated, since involve the loan capital and intern capital invested and interest rate. This discount rate should reflect the payback of the investment done. In the present study the discount rate was considered as a constant interest rare, which value will be mentioned ahead.

Throughout NPV it is possible to predict the cost of the building life cycle for 50 years with different budgets, and it allows to compare, which alternative is more advantageous and with lower cost. Within NPV it is also possible to observe if building maintenance takes into account the quality and durability of materials and if the designed solutions have lower associated costs along its life cycle.

Besides the uncertainty in the economic analysis in this type of studies, two reasons justify the 50 years option for this study: the first one is because is the standard period of buildings service life and the second is because is a representative period that can show the LCC differences between scenarios due to different maintenance actions and its periodicities.

To support this methodology, BIM can play and important role, explained in the next section for building assets management, and after is applied to the case study.

\subsection{BIM in the assets management}

With Building Information Modelling (BIM) the project information modelling obtained decrease the possibility of information loss during design, building and management process [29], as more accurate virtual models of a building are constructed digitally, supporting design through all its phases, allowing better analysis and control than manual processes. When completed, these digital models contain precise geometry and data needed to support the construction, fabrication, and procurement activities through which the building is realised.

When well adopted, BIM facilitates a more integrated design and construction process that results in better quality of buildings at lower costs and reduced project duration. It also improves new capabilities, such as checking a multidisciplinary model for conflicts prior to construction and automatically checking a design for satisfaction of building codes [8].

BIM has benefits for construction stage, such as, BIM tools for coordinating space and schedules and software tools for clash detection providing ways to reveal layout errors in advance, thereby enabling more cost-effective resolutions and fewer expensive change orders [13]. Besides that, the combination of standard Industry Foundation Classes (IFC), BIM, BLCM and web services make possible to arrive to a platform that presents a practical way to realize information, creating, exchanging, sharing and management of all participants of the construction industry.

Different information such as time, costs, safety and quality can be integrated on BIM databases, and by this reason, researchers believe that BIM has a realistic potential to improve construction and to manage and share information during Building Life Cycle [29]. BIM turns possible to improve coordination and management in the work place, due to its easier comprehension of the model, its capacity of detection of errors and omissions in the model, beforehand facilitating its update and avoiding problems, extra costs and time, during the construction phase.

It is also important to note, that BIM is considered a multi-layered socio-technical system, that include technical core and the social part, which combines the man-made technology and the social and institutional consequences of its implementation in society. The technical core of BIM is the software, which enables 3D modelling and information management, in which it is possible insert additional information, such as sustainability and maintenance information, into the model. Autodesk Revit is one of the commercially BIM software available in the market, which allows users to design buildings and its components in 3D/4D environment [37].

In this study, BIM was applied manly for preventive maintenance actions as, for BLCM, BIM provides value in managing relevant data about current building conditions and facilitates the analysis of alternatives. Some building professional designers are embedding data on 


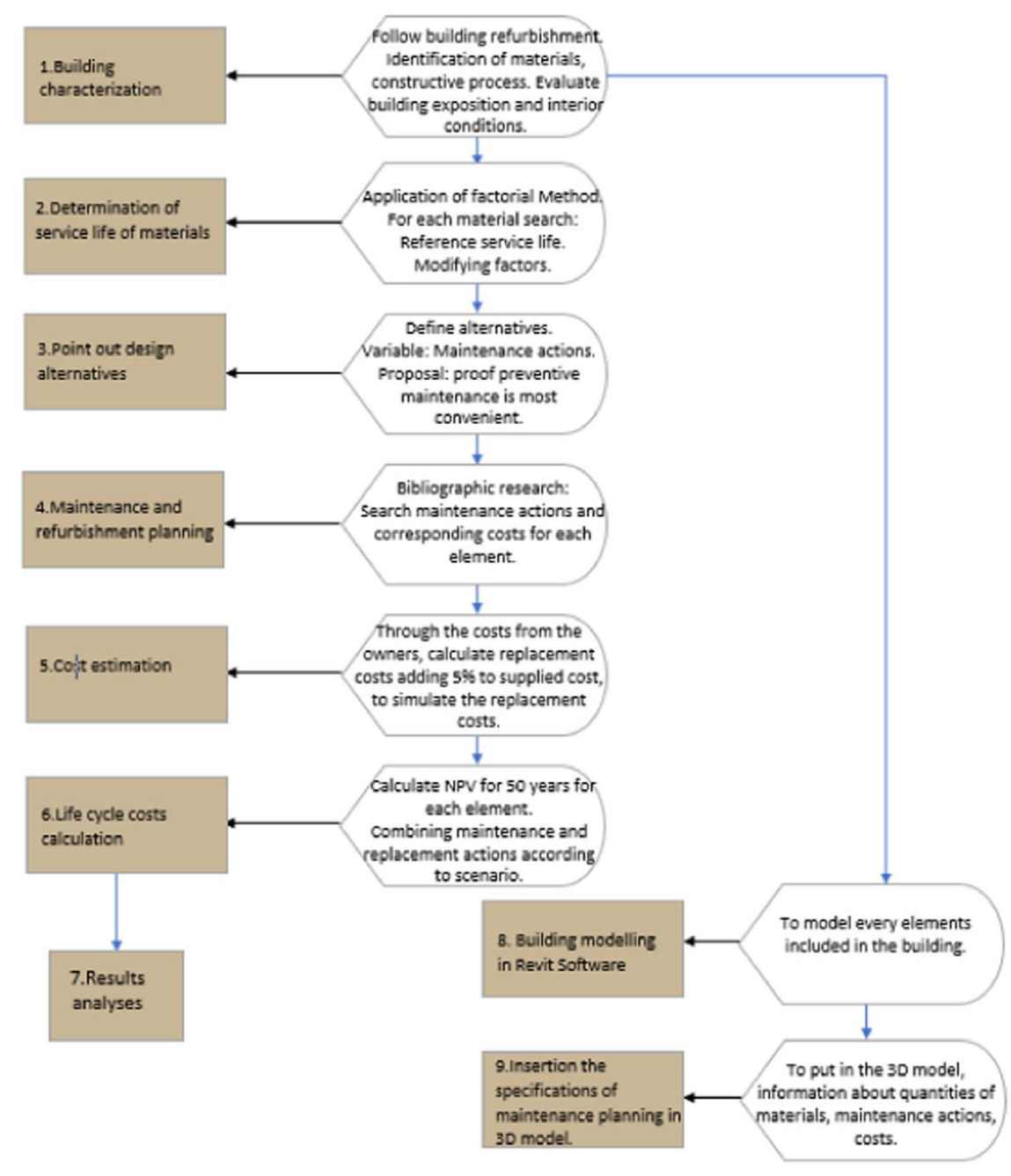

Fig. 1. Flowchart of methodology applied.

life expectancy and replacement costs in BIM models, thereby helping owners to understand the benefits of investing in materials and systems that may cost more initially but have a better payback over the life cycle of the building. Thus, it is possible consider that BIM technology allows to manage information during the entire life cycle of the Architectural, Engineering and Construction industry [36].

Although, in this study, BIM model was developed to support LCC method in refurbishment, the innovation of BIM technology can improve the predicting, managing and monitoring of environmental impacts of construction projects through virtual 3D-BIM models [37]. So, it is possible to conclude that BIM can bring many advantages for LCA and LCC.

\section{Case study}

In this case study, it was considered the refurbishment of a building built in the beginning of the XX century, located in Vila Nova de Gaia, Oporto, Portugal. It was applied the following methodology, represented in the flowchart of Fig. 1:

1. Building characterization;

2. Determination of service Life of materials;

3. Point out design alternatives;

4. Maintenance and refurbishment planning;

5. Costs estimation;

6. Life cycle costs calculation;

7. Results analyses;
8. Building modelling in Revit Software;

9. Insertion the specifications of maintenance planning in 3D model.

\subsection{Building characterization}

The building under study is located in the North of Portugal, implanted above slope in clay ground with rock outcrops, and was subject to a deep intervention of refurbishment in 2016, that was a followed by one of the authors having the opportunity to study and characterize the constructive elements in situ.

It is a traditional building comprising two floors with a structure composed by granite masonry walls, with wood rafter structure in the roof supported on the lateral granite walls. The thickness of granite stone walls varies from $0.50 \mathrm{~m}$ to $0.90 \mathrm{~m}$. The refurbishment of the building included the execution of a galvanized steel sheet as deck permanent formwork and concrete slab (for the first floor) supported on the granite walls. The first floor has hardwood flooring and natural stone coverings on the ground floor, namely, granite and slate. The finishing of interior walls is in painted plaster and the ceilings are mainly in plaster; the exterior walls are only painted. According to the geotechnical survey, the ground water level is at $2.8 \mathrm{~m}$ of depth. Although most of the anomalies identified before the building refurbishment are related with moisture or condensation phenomena, the humidity is due to water infiltration by the cover caused by an undersized design of the gutter. Besides that, the building had aged materials and components that need deep refurbishment to be more safe and modern. Figs. 2-4 show the facades of the building before and after 


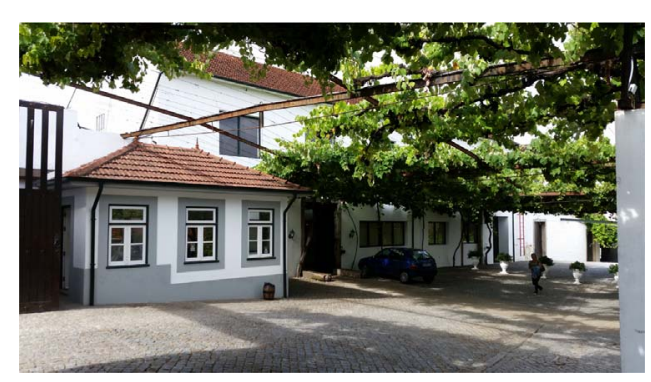

Fig. 2. Building before refurbishment.

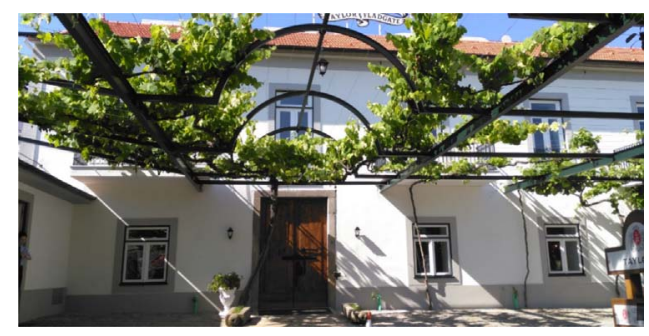

Fig. 3. Building after refurbishment.

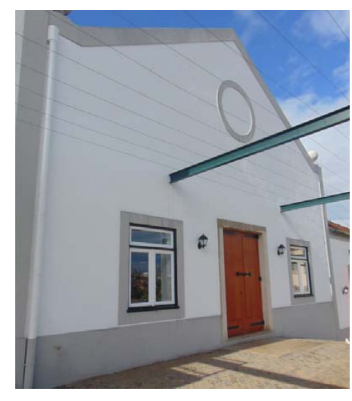

Fig. 4. Building after refurbishment.

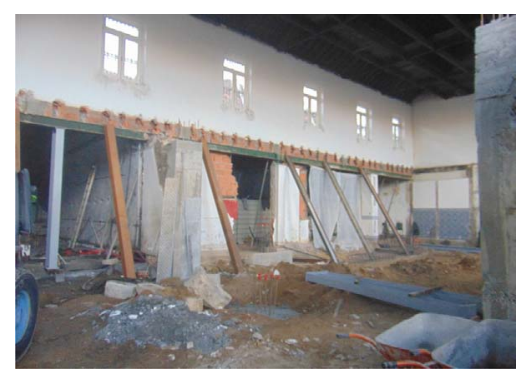

Fig. 5. Building during refurbishment.

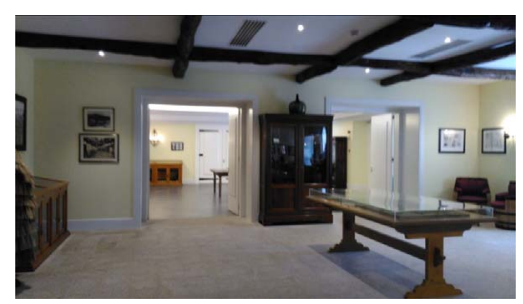

Fig. 6. Building after refurbishment.

the refurbishment, and Figs. 5-7 show the interior of the building during and after refurbishment.

\subsection{Methodology}

To develop this study a BIM-3D Model in Autodesk Revit software

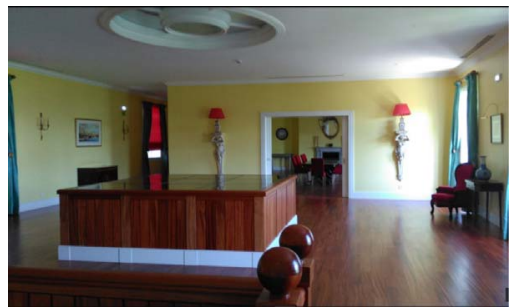

Fig. 7. Building after refurbishment.

was developed. Through the definition of shared parameters, it was possible to associate each refurbishment action to each object in each family in the 3D model. The same was done for the unitary costs of the maintenance works considered. With a schedule it can be also extracted the total maintenance costs of a specific action as well the list of the maintenance works that have to be done including the respective schedule. With the shared parameters and maintenance actions added, the maintenance plan can be done.

To the determination of service life of materials, it was firstly identified the elements object of maintenance, over the building life cycle to keep its good performance. After this, to obtain service life of materials the factorial method was applied, which factors conditioning the RSLC. So, if this factors (A, B, C, D, F, G) can be favourable take the value of 1.2 , unfavourable relative to reference take the value of 0.8 , or it can be considerate as reference conditions taking the value of 1.0 [19]. Therefore, it is necessary to define and characterize a set of conditions and factors that have implications on performance over the life cycle of the element. To do the characterization of the conditions that determine the value to be attributed to each factor, criteria were established for each element source of maintenance: considering its support, the element itself and its finishing, except in cases that it has no finishing or it is not directly related with support.

Between the proposed alternatives, the factors that change are the maintenance factors, and the in-use and environment conditions are maintained. Thus, it is possible to obtain differences in life cycle considering the maintenance actions and just replacements actions. To illustrate the work developed it was chosen the gutter, which three alternatives considered to develop this study are explained in Fig. 8. Alternative 1 consists on building life cycle cost without maintenance actions, this means: the alternative include just costs of replacement of materials at the end of its life cycle. Besides that, in factorial method the factor corresponding to maintenance have an negative influence of 0.8 in the service life, since the lack of maintenance decrease its service life and the service life of boundary materials, since they have interaction. To account this materials interaction a Failure Mode and Effect Analysis considering the causes and effects of the anomalies of the drainage system in surrounding materials was done. Alternative 2 consists on applying reactive maintenance actions during building life cycle that include interventions when materials already have anomalies and its boundary materials in consequence are damaged. This alternative consider reactive maintenance and replacement actions costs of the gutter (main anomaly that causes damage in boundary elements) and surround materials and constructive elements. Regarding factorial method, the modifying factor related with maintenance considered 1.0, since, this type of maintenance has a better influence than Alternative 1 (without maintenance) but worse than Alternative 3 (preventive maintenance). In addition, it was assumed that reactive maintenance actions for surrounding materials and gutter was done each 10 years (value considered), and the gutter replacement is done at the end of its service life. Alternative 3 consists on applying preventive maintenance actions during building life cycle that include the calculation of LCC considering maintenance, inspections, cleaning, and replacement costs. Regarding factorial method, preventive maintenance actions has a positive influence in service life of materials, so, modifying factor related with maintenance take the value 1.2. Besides that, to become this a 


1. Calculation of LCC without
maintenance actions
- Considering the costs of
replacements at the end of the
component life
-At factorial method, consider
the maintenance factor as 0.8
- Considering damage that
causes in surrounding
materials

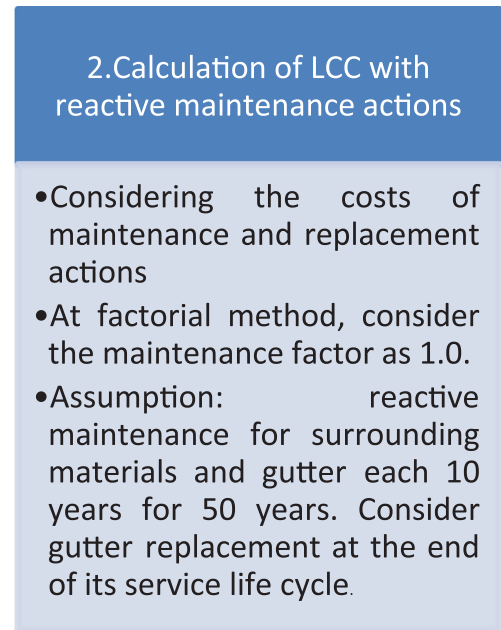

3.Calculation of LCC with

preventive maintenance

actions

- Considering the costs of the maintenance and replacement actions

- At factorial method, consider the maintenance factor as 1.2

- At the degradation curve, consider the increase of performance from the maintenance actions

Fig. 8. Alternatives considered for the calculation of LCC.

stricter process the idea was to define degradation curve considering the increase of performance from the maintenance actions, however, due to lack of data this was not possible. Therefore, to simulate the behaviour of this curve, it was added $5 \%$ to service life of materials when they are subject to preventive maintenance, increasing the period of time to replace material and in this way decreasing the life cycle costs.

Based on these assumptions, the factorial method was applied to evaluate the service life cycle. However, distinguishing these three alternatives became a hard process due to:

In alternative 1, LCC calculation considering damage caused in bordering materials and constructive elements, it is not possible when it needs replacement. Thus, there are no studies or databases that help to know when surrounding materials need replacement due to lack of gutters of galvanized sheet maintenance, so, scenarios were created to make the study of alternative 1 possible. Besides that, the damage of gutters of galvanized sheet depends on several factors, such as surrounding vegetation, pollution and the presence of birds, if it is the case. So, these scenarios allow to have a perspective of the presence of these factors. Following, the considered scenarios are described:

Scenario 1.1: Lack of gutter maintenance, but without any damage over its life cycle.

Scenario 1.2: Lack of gutter maintenance that can cause clogs, broken fixing ring and/or breaking parts of gutters and consequently infiltrations that can cause damage on wall coatings, ceilings and floor coverings. For the replacement of coatings under these conditions 10 years was considered. This case is based on what happens when users/owners do not seek the cause of a material anomaly. Thus, damaged material indirectly through the gutter is substituted and repaired, but the gutter is not, so, the cause of the damage continues until replacement of the gutter, considering it until the end of its service life.

Scenario 1.3: Lack of gutter maintenance, that can cause clogs, broken fixing ring and/or breaking parts of gutters and consequently infiltrations that can cause damage on wall coatings, ceilings and floor coatings. Forecast for the replacements of coatings under these conditions was considered the service life of gutter. Thus, when there are indirect anomalies caused by gutter in other materials, the replacement is done at the same time.

Those scenarios were compared with other alternatives.

In alternative 2 was adopted reactive maintenance actions, meaning that the maintenance is just done, when the anomaly is expressed, and inside this alternative it was proposed two scenarios.
Scenario 2.1: This is a more intrusive scenario that consider the replacing of indirectly damaged materials by gutter in 10 years (as it is possible to see in Tables 8, 9), and it is done a repair of the gutter at the same time. However, it is necessary a gutter replacement at the end of its service life, when its performance ends.

Scenario 2.2: This one considers a less intrusive reactive maintenance, that includes a maintenance of indirectly damaged materials by the gutter in 10 years, and a gutter repair at the same time is done. However, it is necessary the gutter replacement at the end of its service life, when its performance finishes.

10 years was considered but it is very subjective, since the anomaly can appear before this time. 10 years was a period considered, since reactive maintenance refers to work on faults in buildings that have appeared unexpectedly and whose opportunity for intervention could not have been decided earlier $[28,33]$. This is why the value adopted is considered subjective.

In alternative 3 it is difficult to define the curve of life cycle performance of construction defined in ISO 15686-7:2006, so, it is also difficult to demonstrate that the LCC with maintenance is lower than the LCC without maintenance and with reactive maintenance. Thus, associated with each maintenance it was considered a rate that increases the gutter service life for 22 years (based on the $5 \%$ rate previously mentioned).

As it was mentioned before, a period of 50 years for the service life was established to this study, considering that is the standard period of building service life and it was considered a representative period that can show differences between scenarios due to maintenance actions and its periodicities.

Therefore, Table 2 shows estimated service life (ESLC) of each material and of respective alternatives, since service life vary with material type. However, Tables (5-10) depict the LCC calculation, organised by categories (like ceilings replacement, wooden floor replacement), since it is not necessary its service life, but just only the scenarios periodicity.

In addition, an example of the calculation of NPV and LCC is in Tables 3, 4 followed by equation 4 and 5 . It is just an example, since the calculation process with maintenance actions are very extense but follow the same methodology depict in Tables 3, 4.

It was also considered the type of possible subsequent periodic maintenance and refurbishment, necessary to provide a specific level of performance throughout the service life. The results are in Tables 5-7 for the situation without future maintenance, in Tables 8, 9 the costs obtained with reactive maintenance and in Table 10 the results with future preventive maintenance.

Regarding maintenance and refurbishment planning a set of 
Table 2

Reference Service Life of a component (RSLC) and Estimated Service Life of a component (ESLC) each material calculated for each alternative.

\begin{tabular}{|c|c|c|c|c|}
\hline Material & $\begin{array}{l}\text { RSLC } \\
\text { (Years) }\end{array}$ & $\begin{array}{l}\text { ESLC A1 } \\
\text { (Years) }\end{array}$ & $\begin{array}{l}\text { ESLC A2 } \\
\text { (Years) }\end{array}$ & $\begin{array}{l}\text { ESLC A3 } \\
\text { (Years) }\end{array}$ \\
\hline $\begin{array}{l}\text { Galvanized sheet Gutter } \\
\text { and paint }\end{array}$ & 15 & 11 & 12 & 22 \\
\hline Wooden floor & 51 & 37 & 41 & 45 \\
\hline Painting of wooden floor & 20 & 14 & 16 & 18 \\
\hline MDF footer & 20 & 14 & 16 & 18 \\
\hline $\begin{array}{l}\text { Cement plaster of } \\
\text { external walls }\end{array}$ & 25 & 19 & 21 & 23 \\
\hline Painting of external walls & 15 & 11 & 12 & 14 \\
\hline $\begin{array}{l}\text { Cement plaster of interior } \\
\quad \text { walls }\end{array}$ & 41 & 32 & 36 & 40 \\
\hline Painting of interior walls & 15 & 12 & 13 & 15 \\
\hline $\begin{array}{l}\text { Plasterboard of interior } \\
\text { walls }\end{array}$ & 35 & 28 & 31 & 34 \\
\hline $\begin{array}{l}\text { Painting of plasterboard } \\
\text { of interior walls. }\end{array}$ & 10 & 8 & 9 & 10 \\
\hline Ceilings plasterboard & 35 & 28 & 31 & 34 \\
\hline $\begin{array}{l}\text { Painting of ceilings } \\
\text { plasterboard }\end{array}$ & 10 & 8 & 9 & 10 \\
\hline Wooden ceiling & 60 & 48 & 53 & 58 \\
\hline $\begin{array}{l}\text { Painting of wooden } \\
\text { ceiling }\end{array}$ & 20 & 16 & 18 & 20 \\
\hline
\end{tabular}

specifications were developed within the design process to establish preventive maintenance actions [1], and the development of this plans is included in the BIM model.

Considering the alternatives scenarios defined, a comparative economic study was performed, with the life cycle costs calculation. It can be noticed that there is a lack of databases for maintenance costs, so in some cases it was applied a rate above initial cost to estimate the replacement cost of the element. Since in the case of the covering replacement it is necessary remove the initial covering, it was added $5 \%$ to initial cost (provided by owner of this building), achieving the replacement cost of the material (considering the type of the existing materials, $5 \%$ it was an adequate value considered by the work team). The gutter's reference service life to calculate its service life by the factorial method was researched from $[5,26]$.

To predict future costs, it is necessary economic projection and information for the period under analysis, in the present case a 50 year was considered, and there are no projections for such a long period. Another period could be considered, like 10 or 30 years, but do to the interest of the building a 50-year life horizon was considered in order to maximizing the value of the investments. So, a constant $0.2 \%$ [9] interest rate was considered for all projections and calculations. The option for this approach was based on the Eurosystem's Macroeconomic Projections for the Euro Area, once interest rates are indexed to Euribor and have negative projections, with long-term interest rates being revised downwards. Thus, it was decided to consider an average value for the interest rate that reflects the current negative trend and future projections. Moreover, this is a key factor that justify why costs of scenario 1.3 are lower than costs of scenario 1.2.

However, it is possible to see through these results resumed in Fig. 9, as expected, that building life cycle costs without maintenance are higher than with maintenance (around 1078\% comparing scenario 1.2 with alternative 3 ). The application of preventive maintenance actions to building life cycle provoke a saving of $89 \%$ when comparing with alternative 2.1 (intrusive scenario that consider the replacing of indirectly damaged materials by gutter in 10 years, and it is done a repair of the gutter at the same time. The gutter replacement is done at the end of its service life, when its performance ends) and a saving of $79 \%$ with comparing alternative 2.2 (reactive maintenance of indirectly damaged materials by the gutter in 10 years, and a gutter repair at the same time. The gutter replacement done at the end of its service life, when its performance finishes). Besides that, due to the functional use given to the buildings, this is a building with high performance requirements, so it is necessary to keep a perfect performance of materials and equipment, and without maintenance, this cannot be assured. The degradation of materials and consequent corrective maintenance cause greater inconvenience and costs (e.g. a simple problem that can be solved with preventive maintenance, can result in space closure if only solved by corrective maintenance).

\subsection{Results analysis}

A technical and economic analysis comparison of different maintenance strategies and its scenarios (without maintenance, with reactive maintenance and preventive maintenance) is performed. With this analysis, it is possible to answer the question: is it better to invest in solutions that are more durable in design and construction stage to save money throughout the building life cycle and in preventive maintenance to achieve longer service life? And to quantify the long-term costs of maintenance actions?

At this stage, it is possible to analyse and understand the results of LCC methodology application, and comparing alternatives allows to conclude which ones are the most advantageous, with smaller costs and longer building service life [38].

In Table 5 it can be seen that the lower cost corresponds to alternative 1 - scenario 1.1 without maintenance. However, the probability of this scenario is clearly very reduced, because it is unlikely that all materials are in good condition for 50 years, without any abnormality or any issue that conduce to indirect anomalies. However, in this alternative, the scenario 1.2 and 1.3 are very expensive and disadvantageous.

The results have shown that, the alternative 2 with reactive maintenance can be more advantageous than the all life cycle without maintenance, except when the damage is too deep and it has to do a really intrusive reactive maintenance (scenario 2.1 ).

For the application of alternative 3 - preventive maintenance over building life cycle, lead to the increase of durability and service life of components. Regarding life cycle cost, it is possible to show, that there is a saving comparing with other alternatives, since it does not need so many replacements when compared with the alternative 1 and 2 . Besides that, in alternative 3 , through the preventive maintenance, the causes of anomalies and other indirect damages in other materials and constructive elements can be prevented. Some maintenance, for example as cleaning, many times is underestimated and neglected, but are crucial operations [4]. So, some replacements really could be avoided with simple preventive maintenance actions over the life cycle. Concluding, alternative 3 should be adopted to keep the high performance of the building saving money over the building life cycle.

Maintenance is a key element in the buildings management and is an important factor in terms of building life cycle costs, like recognized

Table 3

Example of NPV and LCC calculation.

\begin{tabular}{|c|c|c|c|c|c|c|c|}
\hline Material & Periodicity & quantity & units & replacement unit cost & Initial cost (to 1 st refurbishment) & $\mathrm{NPV}(\mathrm{k}=0.2)$ & $\Sigma$ Cost \\
\hline Galvanized sheet Gutter replacement & 22 & 81.60 & $\mathrm{~m}$ & $38.80 €$ & $3169.00 €$ & $5939.00 €$ & $9109.00 €$ \\
\hline \multirow[t]{2}{*}{ Painting of Galvanized sheet Gutter } & 22 & 71.44 & $\mathrm{~m}$ & $6.80 €$ & $487.60 €$ & $914.00 €$ & $1401.00 €$ \\
\hline & & & & & & Subtotal & $10510.00 €$ \\
\hline
\end{tabular}


Table 4

Detailed calculation of NPV and LCC: Galvanized sheet gutter replacement.

\begin{tabular}{|c|c|c|c|c|c|c|c|}
\hline Material & Periodicity & quantity & units & replacement unit cost & Initial cost (to 1 st refurbishment & $\mathrm{NPV}(4)(\mathrm{k}=0.2)$ & $\Sigma \operatorname{Cost}(5)$ \\
\hline $\begin{array}{l}\text { Galvanized sheet Gutter replacement } \\
N P V=\frac{3169.00}{(1+0.2 \%)^{22}}+\frac{3169.00}{(1+0.2 \%)^{22 \times 2}}(4)\end{array}$ & 22 & 81.60 & $\mathrm{~m}$ & 38.84 & $\begin{array}{l}3169.00 \\
L C C=5939.00+3169.00(5)\end{array}$ & $5939.00 €$ & $9109.00 €$ \\
\hline
\end{tabular}

Table 5

LCC of Scenario 1.1 - alternative 1 (Without maintenance).

\begin{tabular}{|c|c|c|c|c|}
\hline \multicolumn{5}{|l|}{ Scenario 1.1} \\
\hline Material: gutter & $\begin{array}{l}\text { ESLC } \\
\text { (Years) }\end{array}$ & Units & $\begin{array}{l}\text { Initial cost (to 1st } \\
\text { refurbishment }\end{array}$ & $\begin{array}{l}\Sigma \text { Cost : } 50 \\
\text { years }\end{array}$ \\
\hline \multirow[t]{2}{*}{$\begin{array}{l}\text { Galvanized sheet Gutter } \\
\text { and paintreplacement }\end{array}$} & 11 & $\mathrm{~m}$ & $3657.00 €$ & $\begin{array}{l}17 \\
520.00 €\end{array}$ \\
\hline & Total & & & $\begin{array}{l}17 \\
520.00 €\end{array}$ \\
\hline
\end{tabular}

by Flores and Brito [11], and is the only way to increase the lifetime of existent materials. Thus, these actions need to be considered and planned in design stage through maintenance plans, to allow optimisation of resources, time control and minimizing costs over building life cycle (adapted from Colen et al. [4]), and this can be powered using BIM methodology.

\section{Application of BIM to the case study}

In this work, it was decided to model the building in Autodesk Revit software to obtain the maintenance plan, by introducing specific shared parameters how explained in Section 3.2, to conclude about the advantages of BIM for BLCM. Following it is explained what is BIM and its importance for refurbishment and for BLCM.

Building Information Modelling (BIM) is transforming architecture, engineering and construction by providing accurate, timely and relevant information throughout buildings life cycle. While the use of BIM technology for facility management is still developing, its potential to improve the effectiveness of building life cycle management is clear. The challenge faced by the facility management profession is the division between the information used for building design and construction, and the information needed for effective facility management [13].

Figs. 10-13 show the 3D model developed, where it is possible to see handrails, skylights, stairs, roof structure, ceilings, crown moulding, windows and doors, walls, beams structure, clay roof tiles and the rain water drainage system.

\subsection{Insertion the specifications of maintenance planning in $3 D$ model}

BIM is more than a software [20], besides 3D modelling, BIM usage includes the collaboration of resources such as people with their roles, competencies and interests, activities and processes. It is possible to extract tables with material coding and their respective measurement, costs, description, type and many other information. When the model is modified, this information is modified automatically too. So, this 3D model, and to take advantage of this methodology, was developed to introduce maintenance actions to obtain preventive maintenance plans. Through the creation of shared parameters where it is introduced information about maintenance, quantities and unitary cost, it is possible to get schedules. These schedules are automatically extracted from the 3D model and the information updated in the model is automatically updated in the schedules. These schedules are a good way to organise information, since they include materials, quantities of materials, and maintenance actions of each element, its correspondent periodicity and its correspondent costs. An example of a schedule extracted from the model is in Fig. 14.

Note, that the cost is calculate by the schedule when it is extracted, however, this calculation, results from product between area and unitary cost. So, the cost is named cost per area, since in this case, it does not include the maintenance costs. Nevertheless, it is a tool that can be used to develop maintenance plans, since it can help in the development of plan schedules and extract maintenance costs to prepare building and reduce its vulnerability [10].

Besides that, in plants and in 3D model it is possible match the maintenance actions to objects and materials, through annotations tags, how it is possible to see in Figs. 15 and16.

Maintenance actions, periodicity and correspondent costs are information very useful to improve BLCM. This information is able to integrate tables organised by element or category - maintenance plans which aims to satisfy users' needs, increase buildings service life [15] and respecting security and functional requirements taking into account the available budget. Therefore, with this information, it is possible to make the maintenance plans, which it is an advantage for building life cycle.

\section{Conclusions}

\subsection{Approach limitations}

This work aims to calculate service life of materials of an existent building throughout factorial method, to do a research about maintenance actions and maintenance costs for each material and calculate LCC for a period of time of 50 years.

One of the objectives of this study is to proof which type of maintenance is more advantageous for building life cycle. In addition, BIM has used as data and maintenance management methodology, proofing to be a high contribute to building life cycle management. However,

Table 6

LCC of Scenario 1.2 - alternative 1 (Without maintenance).

\begin{tabular}{|c|c|c|c|c|}
\hline \multicolumn{5}{|l|}{ Scenario 1.2} \\
\hline Material: gutter & ESLC (Years) & Units & Initial cost (to 1 st refurbishment & $\Sigma$ Cost :50 years \\
\hline Galvanized sheet Gutter and paintreplacement & 11 & $\mathrm{~m}$ & $3657.00 €$ & $17520.00 €$ \\
\hline Wooden floor coverings replacement & 10 & $\mathrm{~m}^{2}$ & $20026.00 €$ & $114368.00 €$ \\
\hline Ceilings replacement & 10 & $\mathrm{~m}^{2}$ & $15170.00 €$ & $86637.00 €$ \\
\hline MDF footer replacement & 10 & $\mathrm{~m}$ & $2467.00 €$ & $14088.00 €$ \\
\hline \multirow[t]{2}{*}{ Wall coverings and facade } & 10 & $\mathrm{~m}^{2}$ & $17037.00 €$ & $97298.00 €$ \\
\hline & Total & & $58357.07 €$ & $329912.00 €$ \\
\hline
\end{tabular}


Table 7

LCC of Scenario 1.3 - alternative 1 (Without maintenance).

\begin{tabular}{|c|c|c|c|c|}
\hline \multicolumn{5}{|l|}{ Scenario 1.3} \\
\hline Material: gutter & ESLC (Years) & Units & Initial cost (to 1 st refurbishment & $\Sigma$ Cost $: 50$ years \\
\hline Galvanized sheet Gutter and paint replacement & 11 & $\mathrm{~m}$ & $3657.00 €$ & $17520.00 €$ \\
\hline Wooden floor coverings replacement & 11 & $\mathrm{~m}^{2}$ & $20026.00 €$ & $95946.00 €$ \\
\hline Ceilings replacement & 11 & $\mathrm{~m}^{2}$ & $15170.00 €$ & $72681.00 €$ \\
\hline MDF footer replacement & 11 & $\mathrm{~m}$ & $2467.00 €$ & $11819.00 €$ \\
\hline \multirow[t]{2}{*}{ Wall coverings and facade replacement } & 11 & $\mathrm{~m}^{2}$ & $17037.00 €$ & $81625.00 €$ \\
\hline & Total & & $58357.07 €$ & $279591.00 €$ \\
\hline
\end{tabular}

during this work some limitations were found, as following.

Regarding to factorial method, does not provide a reliable service life of materials or components, giving an empirical estimation. So, it is not a stricter method, since the degradation rate of materials is assumed constant, and the method assigns the same weight to different modifying factors that may have different influences in material durability. Besides that, lack of monitoring data about performance of building do not allow to do performance curve. Therefore, the rate attribute to increase the material performance when it has a preventive maintenance is subjective and it can be even unreal.

Regarding to LCC, in this work LCC calculation was done manually, so it revealed a slow and extended process, which is more susceptible to mistakes. Also, the maintenance actions were provided by owners, technicians and proposals were made that could be based on wrong assumptions. Besides that, interest rate attributed to this calculation is subjective too, since there is no projections of this rate for 50 years, and this is a big influence and affects the reliability of these results.

Related to BIM application of this case study, the big limitation that can be found was the software cost, and training of professionals that can work with this software.

\subsection{Final conclusions}

The present approach intends the application of Building Life Cycle Management (BLCM), to a case study in Oporto, Portugal. Life cycle cost and life cycle assessment are included in BLCM, however, the only focus of this work was the life cycle cost. Besides that, it is done the relation between BLCM and BIM. It was concluded that BIM is the product of the BLCM and the digital information created, managed and shared in the construction process. Over this study, it can be seen the contributions of BIM in the BLCM, namely in the management of the information all over the life cycle and in the maintenance management. BIM improve the information and management coordination of the work, but it is necessary its effective application.

So, this study have two allied points: the first one is the proof that the building life cycle management associated to preventive maintenance all over the life cycle is the most advantageous to prolong its service life. Therefore, users have concern about this and engineers must highlight the importance of the maintenance plans in BLCM, in order to encourage its application for all buildings. The second point, it is to show the convenience and the more precision to do maintenance management by BIM. During the construction or refurbishment, it is already possible to model the building and to introduce all information related with the building. The information appears in the 3D model associated to each object. So, after this task and during building life cycle management the user just have to manage the maintenance and update the information.

Some difficulties were found over the work and it is done some final comments about it bellow.

The study analyses the life cycle cost to study the benefits of different alternatives of building maintenance: calculation of building life cycle cost without maintenance actions (where is included just costs of replacement of materials in the end of its life cycle); calculation of building life cycle subject to reactive maintenance actions (include interventions done when materials have already been with anomalies and its surrounded materials damaged); and building life cycle subject to preventive maintenance actions (include maintenance, inspection, clean and replacement costs in the end of materials life). It can be observed, that preventive maintenance is the most economic choice and it is the only that increases the durability of materials and constructive elements.

In this case study, the implementation of the factorial method has a considerable level of subjectivity because it was required to apply empirical information (for creation of modifying factors) collected from the contact with technicians, engineers, and proposals were made that could be based on wrong assumptions.

Regarding factorial method, this study was very conditioning, since it was not easy to find databases of reference service life of very specific traditional materials applied in the building of the case study (which results in generalised materials, such as, sucupira wooden has not the same service life of oak tree but, the wooden was generalised and was attribute a wooden service life), and there is scarcity of factor databases to apply this method accurately. A great subjectivity and difficulties were found during the attribution of each factor value.

The alternatives scenarios show also the high uncertainties in the service life of the components, the building, and the exact year of

Table 8

LCC of scenario 2.1 - alternative 2 (with reactive maintenance).

\begin{tabular}{|c|c|c|c|c|}
\hline \multicolumn{5}{|l|}{ Gutter Life Cycle and LCC with reactive maintenance } \\
\hline Material: gutter & ESLC (Years) & Units & Initial cost (to 1 st refurbishment & $\Sigma$ Cost $: 50$ years \\
\hline Galvanized sheet Gutter and paintreplacement & 12 & $\mathrm{~m}$ & $3657.00 €$ & $17438.00 €$ \\
\hline Wooden floor coverings replacement & 10 & $\mathrm{~m}^{2}$ & $20026.00 €$ & $114369.00 €$ \\
\hline Ceilings and paint replacement & 10 & $\mathrm{~m}^{2}$ & $15170.00 €$ & $86636.00 €$ \\
\hline MDF footer replacement & 10 & $\mathrm{~m}$ & $2467.00 €$ & $14088.00 €$ \\
\hline Wall coverings and facade replacement & 10 & $\mathrm{~m}^{2}$ & $10763.00 €$ & $61466.00 €$ \\
\hline General cleaning and verification & 10 & $\mathrm{~m}$ & $122.00 €$ & $699.00 €$ \\
\hline Verification pending & 10 & $\mathrm{~m}$ & $244.00 €$ & $1398.00 €$ \\
\hline \multirow[t]{2}{*}{ Replacement of protective treatments of metal sheet } & 10 & $\mathrm{~m}$ & $214.00 €$ & $1223.00 €$ \\
\hline & Total & & $52663.00 €$ & $297319.00 €$ \\
\hline
\end{tabular}


Table 9

LCC of scenario 2.2 - alternative 2 (with reactive maintenance).

\begin{tabular}{|c|c|c|c|c|}
\hline \multicolumn{5}{|l|}{ Gutter Life Cycle and LCC with reactive maintenance } \\
\hline Material: gutter & ESLC (Years) & Units & Initial cost (to 1 st refurbishment & $\Sigma$ Cost $: 50$ years \\
\hline Galvanized sheet Gutter and paintreplacement & 12 & $\mathrm{~m}$ & $3657.00 €$ & $17438.00 €$ \\
\hline Ceilings plasterboard and paint replacement & 10 & $\mathrm{~m}^{2}$ & $13061.00 €$ & $74591.00 €$ \\
\hline Wall plasterboard and Painting replacement & 10 & $\mathrm{~m}^{2}$ & $9464.00 €$ & $54050.00 €$ \\
\hline General cleaning and verification & 10 & $\mathrm{~m}$ & $122.00 €$ & $699.00 €$ \\
\hline Verification pending & 10 & $\mathrm{~m}$ & $244.00 €$ & $1398.00 €$ \\
\hline \multirow{2}{*}{ Replacement of protective treatments of galvanized sheet } & 10 & $\mathrm{~m}$ & $214.00 €$ & $1224.00 €$ \\
\hline & Total & & $26762.00 €$ & $149400.00 €$ \\
\hline
\end{tabular}

Table 10

LCC of alternative 3 (with preventive maintenance).

\begin{tabular}{|c|c|c|c|c|}
\hline \multicolumn{5}{|l|}{ Gutter Life Cycle and LCC with maintenance } \\
\hline Material: gutter & ESLC (Years) & Units & Initial cost (to 1 st refurbishment & $\Sigma$ Cost $: 50$ years \\
\hline Galvanized sheet Gutter and paintreplacement & 22 & $\mathrm{~m}$ & $3657.00 €$ & $10510.00 €$ \\
\hline General cleaning and verification & 1 & $\mathrm{~m}$ & $122.00 €$ & $5941.00 €$ \\
\hline Verification pending & 1 & $\mathrm{~m}$ & $244.00 €$ & $11882.00 €$ \\
\hline \multirow[t]{2}{*}{ Replacement of protective treatments of galvanized sheet } & 5 & $\mathrm{~m}$ & $214.00 €$ & $2244.00 €$ \\
\hline & Total & & $4237.00 €$ & $30576.00 €$ \\
\hline
\end{tabular}

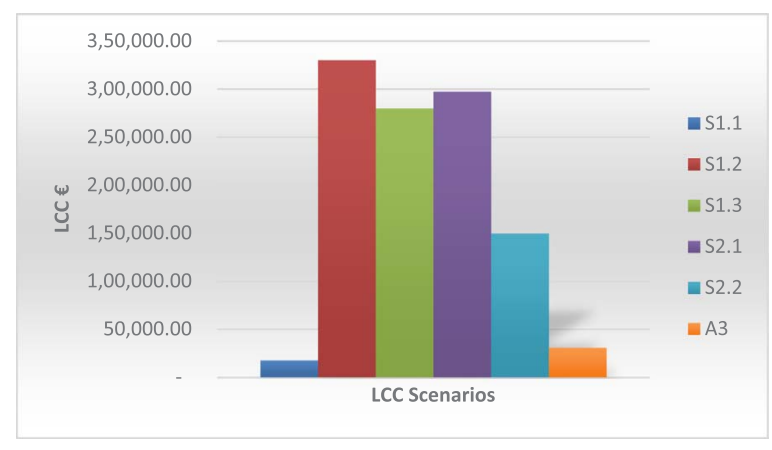

Fig. 9. Comparison of the LCC scenarios.

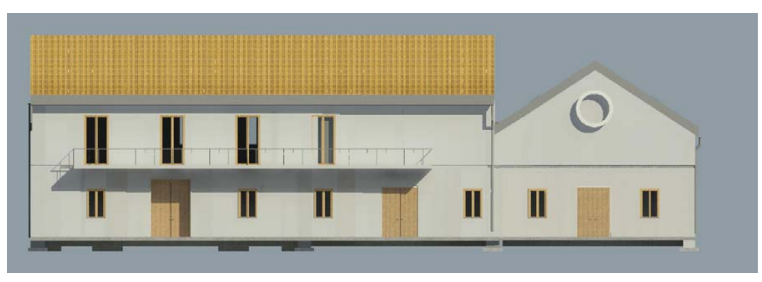

Fig. 10. - 3D model - elevation north.

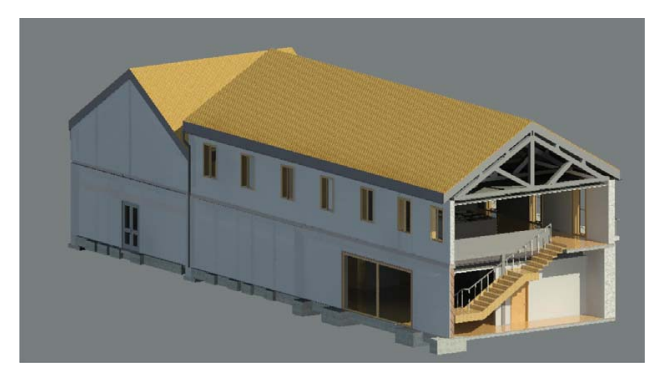

Fig. 11. 3D model - section in elevation East.

replacement. The option for other periods of service life could be also be considered to check the LCC and perform a sensitivity analysis. Besides that, there is an uncertainty between the forecast costs in this study and real costs over the building life cycle since the interest rate is

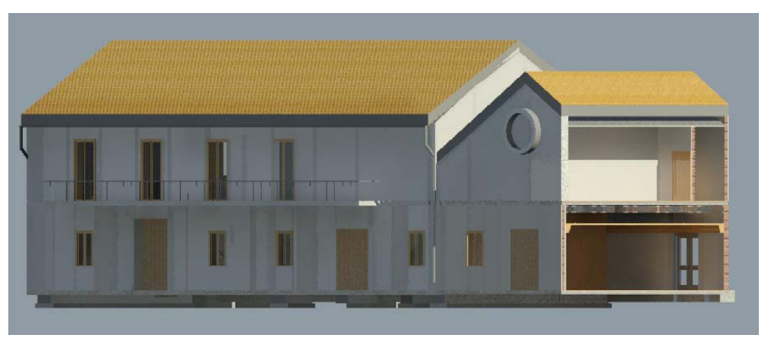

Fig. 12. 3D model - section in elevation West.

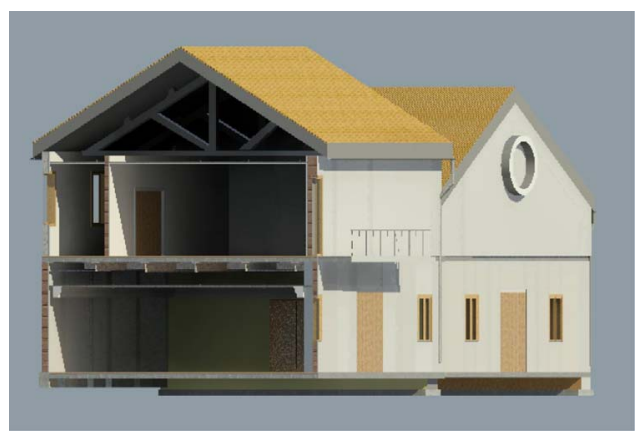

Fig. 13. 3D model - section in the middle of building.

an important influence parameter and being impossible to have projections to so many years.

However, the approach proposed, and the conclusions taken can help practitioners, users and decision-makers to improve the maintenance management within the building life cycle with the highest performance. In the future, the present study can be extended to a representative of Portuguese construction reality and therefore can influence the housing market and all the stakeholder's performance, according to the needs and desires of current users.

In the future, apart from BIM modelling developed, it can be possible to make a deep study that makes possible the definition of performance-degradation curve accurately and study this issue with more attention.

For future studies, we propose the continuation of this work applying LCA to the case study, aiming to know how BIM can improve the study and application of LCA in buildings' refurbishment. 


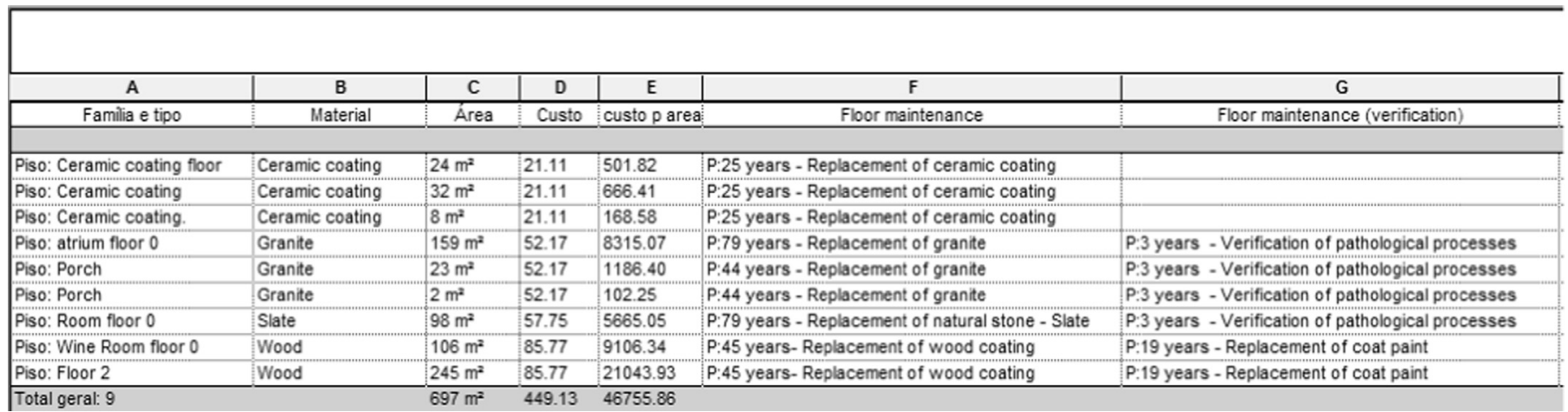

Fig. 14. Schedule extracted by 3D model.

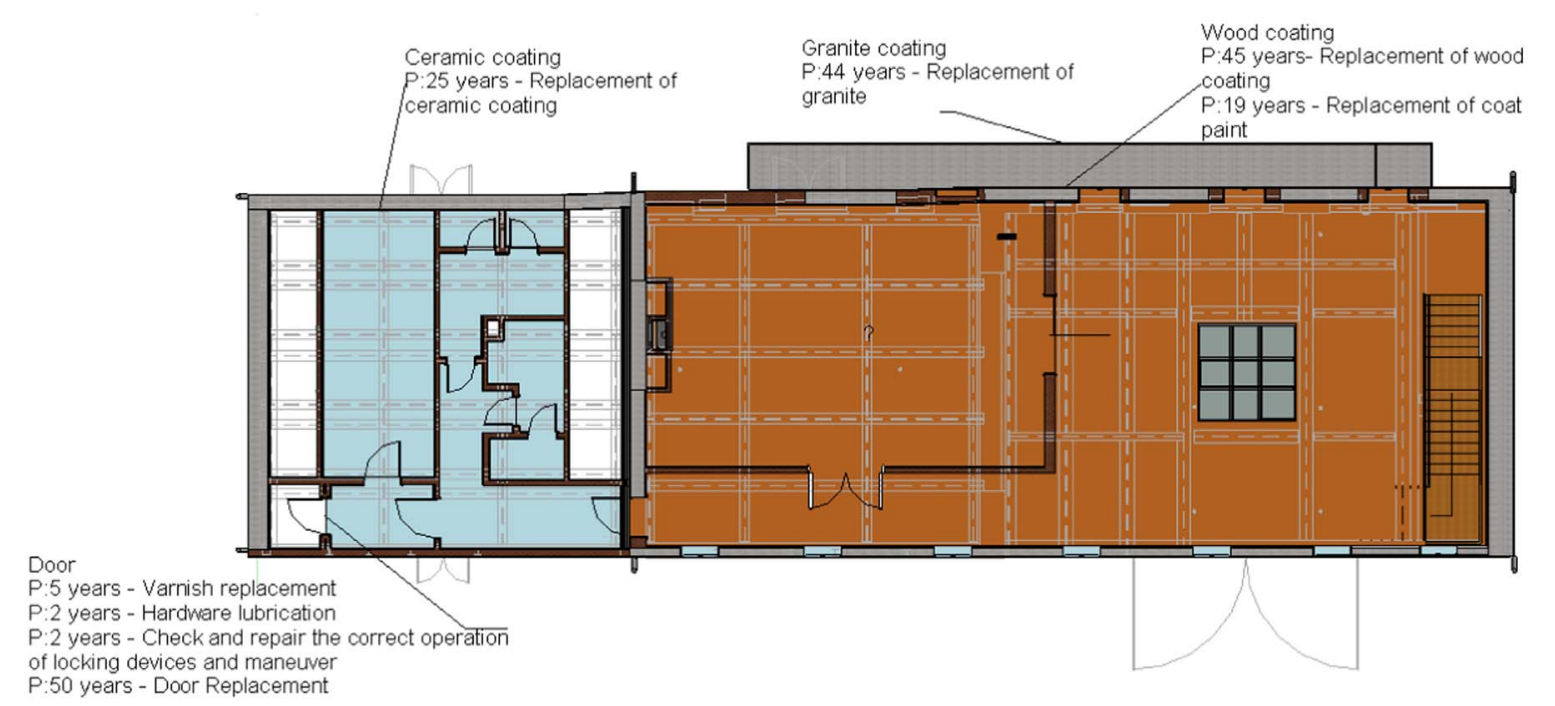

Fig. 15. Maintenance actions and periodicity matched in plan view.

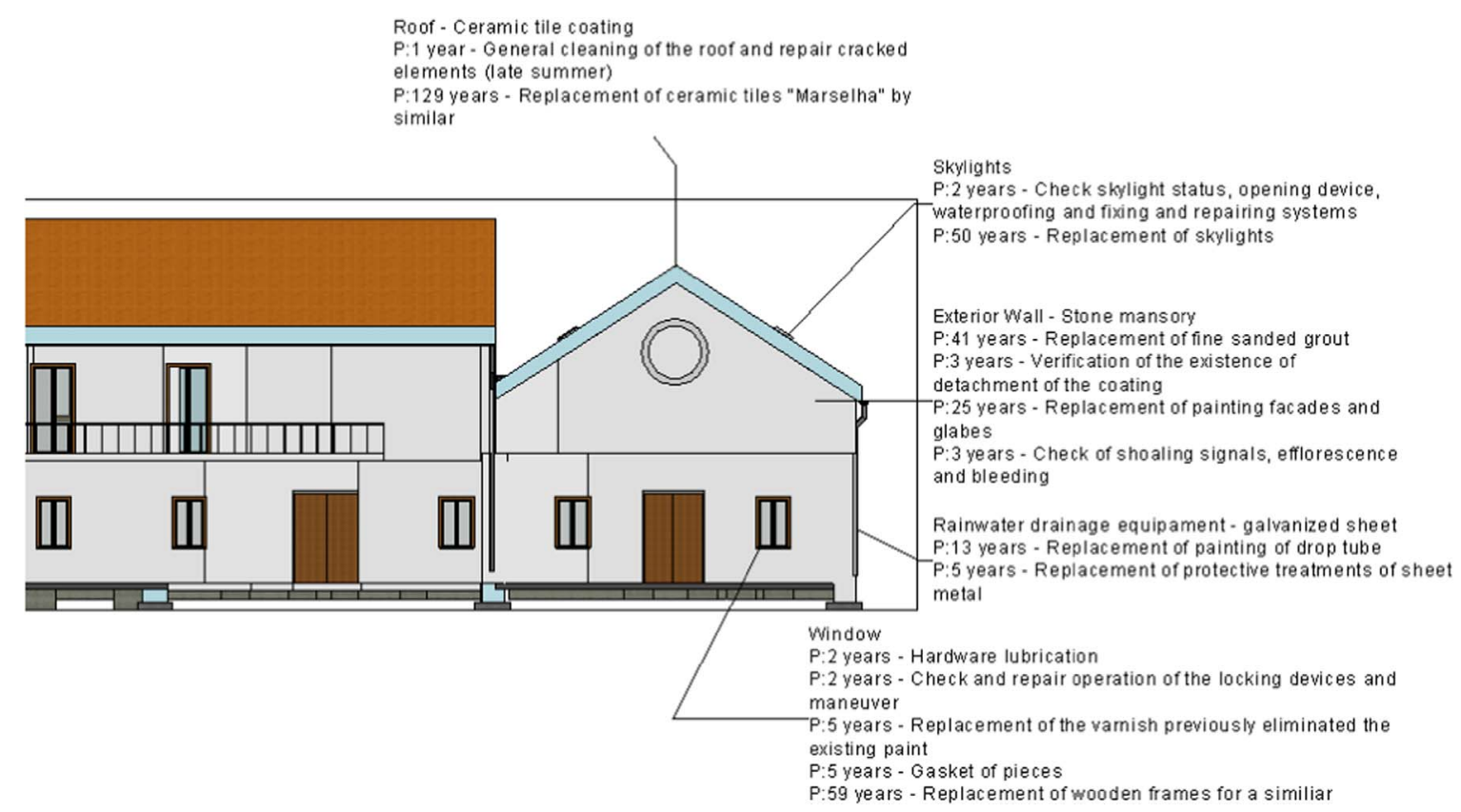

Fig. 16. Maintenance actions and periodicity matched with 3D objects in the model. 


\section{References}

[1] V. Abrantes Almeida, R. Calejo Rodrigues, Schedule approach to improve maintenance of public housing stock, in: Proceedings of the ENHR - Housing policy in central eastern Europe, 1993.

[2] C. Bayer, M. Gamble, R. Genry, S. Joshi, AIA Guide to Building Life Cycle Assessment in Practice, Georgia Institute of Technology, American Institute of Architects, Washington, USA, 2010.

[3] L. Cabeza, L. Rincón, V. Vilariño, G. Pérez, A. Castell, Life cycle assessment (LCA) and life energy analysis (LCEA) of buildings and the building sector: a review, Renew. Sustain. Energy Rev. 29 (2014) 394-416.

[4] I. Colen, J. Brito, A systematic approach for maintenance budgeting of building facades based on predictive strategies, Constr. Build. Mater. 24 (9) (2010) 1718-1729.

[5] M. Di Prizio, F. Rodrigues, J. Matos, A. Simões, A. Costa, R. Vicente, M. Álvares, J. Ferreira - Management model of building maintenance, REHABEND 2016, CONGRESO EURO - AMERICANO REHABEND 2016, in: Luis Villegas, Ignacio Lombillo, Haydee Blanco, Yosbel Boffill (eds.), Patología de la Construcción, Tecnología de la Rehabilitación y Gestión del Patrimonio, 2016, pp. 2230-2238. 2427 Maio, 2016, Burgos, Espanha. ISBN: 978-84-608-7941-1 (Digital Book of Articles).

[6] W. Dixon, What is Whole Life Cycle Costing, Life Cycle Analysis and Life Cycle Costing? WD Re-Thinking Ltd. Consulted on 4 June 2016:availablein 〈https:// www.google.pt/url?Sa $=$ t\&rct $=$ j\&q $=$ \&esrc $=$ s\&source $=$ web\&cd $=1 \& c a d=$ rja\&uact $=8 \&$ ved $=$ 0ahUKEwjC_Zy97MzVAhVG7hoKHZpgD5oQFggrMAA\&url = https\%3A\%2F\%2Fwww.willmottdixon.co.uk\%2Fasset $\% 2$ F9449\%2Fdownload \%3F1424952248\&usg = AFQjCNENNJlodslh-Xdyuvf1om2EXPzn1A〉, 2012.

[7] M. Duraibi, FM in BUILDING LIFE CYCLE MEFMA -Middle East Facility Management Association. Presented by Arch Mohammad Al Duraibi CEO - Da'em Real state Investment Company One of Manafea Golding Group, 2016.

[8] C. Eastman, P. Teicholz, R. Sacks, K. Liston, BIM Handbook a Guide to Building Information Modeling for Owners, Managers, Designers, Engineers and Contractors, : John Wiley and Sons Ltd, New Jersey, 2011.

[9] European Central Bank, Eurosystem Staff Macroeconomic Projections for the Euro Area, Frankfurt am Main, Alemanha, 2016.

[10] B. Feilden, Conservation of Historic Buildings, Third edition, Architectural Press, 2003.

[11] I. Flores, J. Brito, Maintenance of current buildings - State of Art. CONSTRUCTION 2001, Lisbon (Comunication) (In Portuguese), 2001.

[12] I. Flores-Colen, J. Brito, S. Madureira, S. Morgado, Pro-active maintenance plans for building envelope, Int. J. TECHITT - Struct. Constr.- Spec. CONPAT 201514 (39) (2015) 40-49 (In Portuguese).

[13] FM. BIM: Revolutionizing Building Life Cycle Management. Article Magazine, Consulted on 4 June 2016 available in 〈http://fmlink.com/articles/bimrevolutionizing-building-life-cycle-management/ $\rangle$.

[14] Sieglind K. Fuller, Stephen R. Petersen, Life-Cycle Costing Manual for the Federal Energy Mangement Program, 1996 edition, NIST Handbook, 1996.

[15] H. Hon Yin Lee, D. Scott, Overview of maintenance strategy acceptable maintenance standart and resources from a building maintenance operation perspective, J. Build. Apprais. 2009 (2008) 269-278.

[16] ISO, - ISO 15686-1 (2008). Buildings and constructed assets - Service-life planning - Part 1: General principles, 2008.

[17] ISO, - ISO 15686-5 (2008). Buildings and constructed assets - Service-life planning - Part 5: Life- cycle costing, 2008.

[18] ISO 15686-7, Buildings and constructed assets - Service-life planning - Part 7:
Performance evaluation for feedback of service life data from practice, 2006.

[19] ISO, - ISO 15686-8 (2008). Buildings and constructed assets - Service-life planning - Part 8: Reference service-life estimation, 2008.

[20] E. Johansson, D. Haftor, B. Magnusson, J. Rosvall, On Building Information Modeling: An Explorative Study, Department of Informatics and Department of Construction Technology, Linnaeus University, Linnaeus University Press Växjö, Sweden, 2014.

[21] LCP, consulted on 4, June 2016. available in 〈http://www.tandfonline.com/doi/ full/10.1080/15732471003594427〉.

[23] A. Lemer, Life Cycle Costing: for the Analysis, Management and Maintenance of Civil Engineering Infrastructure, Constr. Manag. Econ. 33 (8) (2015) 689-691.

[24] C. Lopes, Construction Durability - Prediction of the Service life of Envelope Ceramic Coatings (Master thesis in Civil Engineering), Faculdade de Engenharia do Porto, OPorto, 2009 (In Portuguese).

[25] R. Mateus, Assessment of Construction Sustainability: Proposals for the Sustainable Development of Buildings (Ph.D. Thesis in Civil Engineering) in Civil Engineering, University of Minho, Braga, 2009 (In Portuguese).

[26] J. Matos, F. Rodrigues, M. Di Prizio, A. Costa, A. Simões, M. Álvares, J. Ferreira, R. Vicente, Diagnosis and inspection: support to maintenance and management. CINPAR2016 - XII International conference on Structural Repair and Rehabilitation, Porto, Portugal, 26-29 October 2016. ISBN: 978-972-752-203-3, 2016.

[27] E. Mora, Life cycle, sustainability and the transcendent quality of building materials. Departamento de Ingenieria de la Construccion y Proyectos de Ingenieria civil, Valencia Polytechnic University, Spain, Build. Environ. 42 (2007) (2005) 1329-1334.

[28] J. Morgado, I. Flores-Colen, J. Brito, A. Silva, Maintenance programmes for flat roofs in existing buildings, Prop. Manag. 35 (Issue: 3) (2017) 339-362, http://dx. doi.org/10.1108/PM-08-2016-0040.

[29] L. Qing, T. Tao, W. Ping, Study in building lifecycle management platform based on BIM. Institute of Project management of school of mechanics and civil engineering, China University of mining and technology, Xuzhou, Jiangsu, China, Res. J. Appl. Sci., Eng. Technol. 7 (1) (2014) 1-8.

[30] A. Saaksvuori, A. Immonem, Product Life Cycle Management, Springer, 2008.

[31] J. Schade, Life Cycle Cost Calculation Models for Buildings, Lulea University of Technology, 2007.

[32] A. Silva, J. Brito, P. de; Gaspar, Methodologies for Service Life Prediction of Buildings, Green Energy and Technology, Springer, 2016.

[33] A. Simões, A. Costa, F. Rodrigues, H. Varum, M. Matos, R. Vicente, Management and preventive maintenance of municipal social housing building stock. Editors: Department of Civil Engineering of University of Aveiro and Domus Social, EM (In Portuguese), 2015. ISBN: 978-989-20-5494-0, 2015.

[34] H. Souza, Life Cycle Assessment and Service Life Influence of Timber and Concrete Posts in the Electrical Distribution System (Master thesis in Civil Engineering), Federal University of Bahia, 2014.

[35] SULB, Guidelines for Life Cycle Cost Analysis, Stanford University Land and Buildings, 2005.

[36] R. Vanlande, C. Nicolle, C. Cruz, IFC and building lifecycle management, Autom. Constr. 18 (2008) (2008) 70-78.

[37] J. Wong, J. Zhou, Enhancing environmental sustainability over building life cycles through green BIM: a review. Department of Building and Real Estate, the Hong Kong technic University, Autom. Constr. 57 (2015) (2015) 156-165.

[38] D. Woodward, Life cycle costing - theory, information acquisition and application. Staffordshire University Business School, UK, Int. J. Proj. Manag. 15 (6) (1997) $335-344$. 